\title{
Hypertension and Serum Mg in the Patients with Diabetes and Coronary Heart Disease
}

\author{
Norio Nagase
}

\begin{abstract}
Interrelations between hypertension (HT), ischemic heart disease (IHD) and diabetes mellitus (DM) were investigated in the diabetic subjects without IHD (DM group) or with IHD (DM+ IHD group) and subjects with IHD (IHD group) which were not complicated with DM. 1. The incidence of hypertension of DM group, DM + IHD group and IHD group is 40, 54, 38\% respectively. 2. The incidence of hyperlipidemia of DM group, DM + IHD group and IHD group is 55, 71, 56\% respectively. 3. Serum Mg levels of DM $(1.9 \pm 0.37 \mathrm{mg} / \mathrm{dl}), \mathrm{DM}+$ IHD $(1.8 \pm 0.23)$ and IHD $(1.9 \pm 0.33)$ were significantly lower than that of normal control $(2.3 \pm 0.32)$. 4. Serum $\mathrm{Mg}$ level of poorly controlled diabetic patients is lower than that of well controlled diabetic patients. These results suggested that Magnesium deficient state is one of the cause of insulin resistancy. (Hypertens Res 1996; 19 Suppl. I: S65-S68)
\end{abstract}

Key Words: diabetes mellitus, ischemic heart disease, serum $\mathrm{Mg}$, insulin resistance

Studies about interrelations between serum Magnesium levels and diabetes mellitus (DM) and ischemic heart disease (IHD) were performed.

First, the experiments used animal model of non insulin dependent diabetes mellitus will describe. These experiments were performed in the accordance with institutional guidelines.

KK mice were originally established in Japan (1). This mice showed mild obesity, mild diabetes, cataract, and reported that they have glomerular lesions similar to those in diabetic nephropathy (2).

\section{Methods}

KK mice were used and divided into two groups. One group (KK) was given laboratory chow OA-2 (Clea, Japan) and tap water, and another group $\left(\mathrm{KK}(\mathrm{Mg})\right.$ ) was given $\mathrm{OA}-2$ and $1 \% \mathrm{MgCl}_{2}$ solution to drink. And control mice were given OA-2 and tap water.

After $12 \mathrm{~h}$ of starvation, $\mathrm{KK}$ and control mice were given $2 \mathrm{~g}$ of glucose per $\mathrm{kg}$ body weight intraperitoneally, then blood samples were drawn from tail vein $0,30,60,120 \mathrm{~min}$ after. Blood glucose was measured by the glucose oxidase method.

The plasma immuno reactive insulin (IRI) levels were measured by a two-antibody method. The serum total cholesterol and triglyceride levels were measured by enzymatic methods with kits from Wako Japan.

Histopathological examination was performed. The heart of KK mice were fixed in $10 \%$ neutral buffered formalin, embedded in paraffin then thin sliced section were made. These sections were stained with hematoxylin-eosin, Azan, Kossa or periodic acid Schiff stain and examined by light microscope.

After ashing by an electrical oven or concentrated nitric acid, the $\mathrm{Ca}$ and $\mathrm{Mg}$ contents of the plasma, erythrocyte and myocardium were measured with an atomic absorption spectrometer.

\section{Results}

Table 1 shows blood glucose, plasma immuno reactive insulin (IRI) and serum lipids levels of KK and control mice.

KK shows hyperglycemia and hyperinsulinemia in glucose tolerance test. The mean value for the sum of blood glucose of KK is significantly higher than that of control, and tendency to increase with age. The plasma IRI level of KK was also significantly higher than that of control.

Serum total cholesterol level was significantly higher than control at age 30 , and serum triglyceride level is significantly higher at age 20 and 30 weeks.

KK showed marked white patchy calcium deposit on the surface of the heart, but there were no calcium deposits in the liver, lungs, spleen and kidneys. Epicardial calcification was seen from 5 weeks old and at 16 weeks old it was seen in about one third of the male and half of the female.

KK mice have myocardial disorders, such as myocardial degeneration, necrosis, fibrosis and epicardial calcification, but they have not an accumulation of PAS-positive materials.

Table 2 shows that $\mathrm{Mg}$ and $\mathrm{Ca}$ contents in serum, erythrocyte and myocardium of control, $\mathrm{KK}$ and $\mathrm{KK}(\mathrm{Mg})$ mice. The $\mathrm{Mg}$ content of the serum of $\mathrm{KK}$

From the Internal Medicine, National Sanatorium Higashi Tokushima Hospital, Tokushima, Japan.

Address for Reprints: Norio Nagase, Internal Medicine, National Sanatorium Higashi Tokushima Hospital, 1-1 Ohmukaikita, Ootera, Itano-cho, Itano-gun, Tokushima 779-01, Japan. 
Table 1. Sum of the Blood Glucose in Glucose Tolerance Test, Plasma IRI, Serum Total Cholesterol and Serum Triglyceride Levels

\begin{tabular}{lccccc}
\hline & Age & $\Sigma \mathrm{BG}(\mathrm{mg} / \mathrm{dl})$ & IRI $(\mu \mathrm{U} / \mathrm{ml})$ & TCh $(\mathrm{mg} / \mathrm{dl})$ & $\mathrm{TG}(\mathrm{mg} / \mathrm{dl})$ \\
\hline Control & 8 & $433 \pm 13.1$ & $35.1 \pm 1.0$ & $110 \pm 2.7$ & $129 \pm 5.6$ \\
& 20 & $460 \pm 13.6$ & $31.2 \pm 5.3$ & $121 \pm 7.6$ & $155 \pm 8.3$ \\
KK & 30 & $473 \pm 15.9$ & $37.8 \pm 3.8$ & $112 \pm 6.3$ & $139 \pm 11.5$ \\
& 8 & $713 \pm 26.9^{* *}$ & $183 \pm 8.4^{\dagger}$ & $137 \pm 4.3$ & $159 \pm 6.3$ \\
& 20 & $890 \pm 93.3^{* *}$ & $205 \pm 9.6^{\dagger}$ & $170 \pm 6.4^{* *}$ & $275 \pm 23.3$ \\
\hline
\end{tabular}

$\Sigma$ BG: sum of blood glucose levels in glucose tolerance test; IRI: immunoreactive insulin; TCh: total cholesterol; TG: triglyceride. The values are means \pm standard errors. Significance of differences was KK $v s$. control mice. ${ }^{* *} p<0.01,{ }^{\dagger} p<$ 0.001 .

Table 2. Ca and Mg Contents of the Serum, Erythrocyte and Myocardium in KK, KK(Mg) and Control Mice

\begin{tabular}{|c|c|c|c|}
\hline Mice & $\operatorname{Serum}(\mathrm{mg} / \mathrm{dl})$ & Erythrocyte(mg/dl) & Myocardium(mg/100g tissue) \\
\hline \multicolumn{4}{|l|}{$\mathrm{Ca}$} \\
\hline Control & $7.5 \pm 0.2$ & $3.1 \pm 0.4$ & $7.2 \pm 0.4$ \\
\hline KK & $7.6 \pm 0.2$ & $3.7 \pm 0.6$ & $198 \pm 35 * *$ \\
\hline $\mathrm{KK}(\mathrm{Mg})$ & $7.5 \pm 0.2$ & $4.1 \pm 0.3$ & $11.2 \pm 3.6^{* *}$ \\
\hline \multicolumn{4}{|l|}{$\mathrm{Mg}$} \\
\hline Control & $2.1 \pm 0.1$ & $4.5 \pm 0.2$ & $23.4 \pm 0.8$ \\
\hline KK & $2.0 \pm 0.1$ & $4.0 \pm 0.2 *$ & $18.0 \pm 0.6^{* *}$ \\
\hline $\mathrm{KK}(\mathrm{Mg})$ & $2.1 \pm 0.1$ & $5.0 \pm 0.3 * *$ & $24.6 \pm 3.6 * *$ \\
\hline
\end{tabular}

Values are mean \pm standard error. Significance of the differences was between $\mathrm{KK} v s$. control or $\mathrm{KK} v s . \mathrm{KK}(\mathrm{Mg}) .{ }^{*} p<$ $0.05, * * p<0.01$.

Table 3. Incidences of Epicardial Calcification in KK and KK(Mg) Mice

\begin{tabular}{lrrrrr}
\hline \multicolumn{1}{c}{ Mice } & 5 wk & 8 wk & 12 wk & 16 wk & 20 wk \\
\hline KK male & 2.1 & 15.4 & 26.9 & 32.2 & 32.6 \\
KK female & 13.0 & 27.3 & 37.9 & 58.8 & 47.8 \\
KK $(\mathrm{Mg})$ male & 0 & 6.7 & 8.0 & 7.1 & 11.1 \\
KK $(\mathrm{Mg})$ female & 0 & 5.0 & 11.1 & 8.3 & 10.0 \\
\hline
\end{tabular}

was slightly lower than that of control but was not statistically significant. The $\mathrm{Mg}$ contents of erythrocyte and myocardium of KK were significantly lower than those of control.

The Ca contents of the plasma and erythrocyte of KK were similar to those of control, but the $\mathrm{Ca}$ content of the myocardium was significantly increased.

The Mg contents of serum, erythrocyte and myocardium of $\mathrm{KK}(\mathrm{Mg})$ were similar to those of control, but erythrocyte and myocardial $\mathrm{Mg}$ contents were significantly higher than those of KK.

The Ca content of the serum and erythrocyte of these three mice were similar, but the myocardial content of $\mathrm{KK}(\mathrm{Mg})$ was significantly lower than that of $\mathrm{KK}$, and was not significantly different from that of control.

Table 3 shows the incidences of epicardial calcification of $\mathrm{KK}$ and $\mathrm{KK}(\mathrm{Mg})$.
Epicardial calcification was seen from week 5 in $\mathrm{KK}$, and older than 16 weeks old it was found in about one-third of the male and half of the female. The incidences of epicardial calcification of $\mathrm{KK}(\mathrm{Mg})$ were significantly decreased to $10 \%$.

\section{Discussion}

KK mice showed hyperglycemia, hyperinsulinemia in glucose tolerance test and hyperlipidemia. Their fasting blood glucose level was not so high, but their fasting plasma IRI levels were significantly higher than control mice. These results suggested that $\mathrm{KK}$ has insulin resistant state.

And KK had myocardial disorders such as degeneration, fibrosis and epicardial calcification. KK showed epicardial calcification from 5 weeks old and myocardial disorders from 16 weeks old.

In $\mathrm{KK}$, the Ca content of the myocardium was increased, and the $\mathrm{Mg}$ contents of the myocardium and erythrocyte were decreased markedly. In the body $\mathrm{Mg}$ was distributed in the bone and intracellular space and only $1-2 \%$ of total $\mathrm{Mg}$ was distributed in the extracellular fluid. So the serum $\mathrm{Mg}$ level does not reflect the $\mathrm{Mg}$ deficient state of the body. The measurement of tissue $\mathrm{Mg}$ content was necessary to diagnose $\mathrm{Mg}$ deficiency.

The addition of $\mathrm{Mg}$ to drinking water suppressed epicardial calcification and myocardial disorders in $\mathrm{KK}$ markedly. In $\mathrm{KK}(\mathrm{Mg})$ the $\mathrm{Ca}$ contents of the 
Table 4. Age and Incidences of Smokers and Hypertension in DM, DM + IHD and IHD Groups

\begin{tabular}{lccc}
\hline & Age(year old) & Smoker(\%) & Hypertension(\%) \\
\hline DM & $56 \pm 14$ & 33 & 40 \\
DM+IHD & $59 \pm 12$ & 36 & 54 \\
IHD & $61 \pm 11$ & 59 & 38 \\
\hline
\end{tabular}

Values are mean \pm standard deviation.

myocardium was significantly decreased and the $\mathrm{Mg}$ contents of erythrocyte and myocardium were normalized. These findings suggested that there was close correlation between $\mathrm{Mg}$ deficient state and myocardial disorders in KK.

The cause of $\mathrm{Mg}$ deficiency in $\mathrm{KK}$ was not clearly known. The $\mathrm{Mg}$ absorption from the small intestine was decreased in the streptozotocin induced diabetic rats, and in the alloxan induced diabetic rabbits it was reported that serum $\mathrm{Mg}$ level was decreased and urinary excretion of $\mathrm{Mg}$ was increased (3).

These data suggested that there was close relationship between diabetes and the $\mathrm{Mg}$ deficient state.

Second, the clinical examination about $\mathrm{Mg}$ and diabetes mellitus and ischemic heart disease was performed in admitted or ambulatory patients.

Interrelations between hypertension (HT), ischemic heart disease (IHD) and diabetes mellitus were investigated in the diabetic subjects without IHD or with IHD and subjects with IHD which were not complicated with DM.

\section{Methods and Subjects}

The patients were divided into 3 groups.

1. DM group: diabetic subjects without IHD consisted with 202 patients, 98 males and 104 females, and their electrocardiograms had no signs of myocardial ischemia.

2. DM + IHD group: diabetic subjects with IHD consisted with 32 patients, 20 males and 12 females.

3. IHD group: ischemic heart disease without DM consisted with 42 patients, 32 males and 10 females.

DM was defined that be treated as diabetes or showed diabetic pattern in glucose tolerance test.

IHD was defined that had the history of myocardial infarction or had significant stenotic lesions (more than $75 \%$ in diameter) in coronary angiography.

This study was approved by the institutional ethical committee and all patients were given informed consent and agreed with to participate this study.

\section{Results}

Table 4 shows mean ages, incidences of smokers and hypertension.

There was no statistical differences in these three groups, in ages, smokers and hypertension, but the incidence of smokers in IHD group was 59\% and slightly higher than other two groups, and the incidence of hypertension in DM+IHD group was 54\% and slightly higher than others.

Table 5 shows therapeutic method for diabetes mellitus, $54 \%$ of DM + IHD group were treated with diet therapy only, and $78 \%$ of DM group were given oral agents or insulin. There were no statistical differences in the levels of fasting blood glucose and glycated hemoglobin of DM group and DM + IHD group, but slightly lower in DM+IHD group.

In DM group the incidences of retinopathy, nephropathy and neuropathy were $60 \%, 33 \%, 22 \%$ respectively and in DM + IHD group were 50\%, $12 \%, 14 \%$. The incidences of retinopathy and neuropathy were similar in two groups and nephropathy was slightly lower in DM+IHD group.

The serum lipid levels of these three groups were indicated in Table 6.

Serum total cholesterol levels were similar and serum triglyceride level is significantly higher in DM + IHD group, and serum HDL cholesterol level is lower in DM + IHD group and significantly lower in IHD group.

The dyslipidemia was defined as total cholesterol level was higher than $230 \mathrm{mg} / \mathrm{dl}$, or triglyceride level was higher than $160 \mathrm{mg} / \mathrm{dl}$ HDL cholesterol level was lower than $40 \mathrm{mg} / \mathrm{dl}$. The incidence of dyslipidemia was $55 \%$ in DM group, $71 \%$ in DM + IHD group and $56 \%$ in IHD group, those incidences were very high.

Table 7 shows $\mathrm{Mg}$ levels of serum and erythrocyte. Serum Mg levels were $1.9 \pm 0.37$ in DM group, $1.8 \pm 0.23$ in DM + IHD group, $1.9 \pm 0.33$ in IHD group respectively, and these data was significantly lower than that of normal control $(2.3 \pm 0.32 \mathrm{mg} / \mathrm{dl})$. However, $\mathrm{Mg}$ levels of erythrocyte were similar in these three groups, and not different from normal control.

In diabetic patients there was tendency of negative correlation between serum magnesium level and $\mathrm{HbA}_{1 \mathrm{c}}$ level.

Serum $\mathrm{Mg}$ in well controlled patients whose $\mathrm{HbA}_{1 \mathrm{c}}$ level was lower than $6 \%$ was $2.0 \pm 0.2 \mathrm{mg} / \mathrm{dl}$, in poorly controlled patients whose $\mathrm{HbA}_{1 \mathrm{c}}$ was higher than $10 \%$ was $1.8 \pm 0.2 \mathrm{mg} / \mathrm{dl}$.

\section{Discussion}

The incidence of smoker was slightly higher in IHD group but not so high compared with normal populations. However, the incidences of hypertension in these three group were high compared with normal populations.

Diabetic state of DM and DM + IHD group were compared, $54 \%$ of DM + IHD group and $22 \%$ of DM group were treated with diet therapy and $14 \%$ of DM + IHD group and 34\% of DM group were treated with insulin. This result suggested that many of DM + IHD group can secrete insulin from their own pancreas and the incidence of diabetic complication were similar in these two group. The fasting blood glucose level and the level of glycated hemoglobin were slightly higher in DM group than in DM + IHD group. These results suggested that 
Table 5. Therapy for DM and FBG and $\mathrm{HbA}_{1 \mathrm{c}}$ Levels in DM and DM+IHD Group

\begin{tabular}{lccccc}
\hline & Diet $(\%)$ & Oral agents(\%) & Insulin(\%) & FBG(mg/dl) & HbA $_{1 \mathrm{c}}(\%)$ \\
\hline DM & 22 & 44 & 34 & $169 \pm 69$ & $8.1 \pm 1.8$ \\
DM + IHD & 54 & 32 & 14 & $155 \pm 56$ & $7.3 \pm 1.9$ \\
\hline
\end{tabular}

FBG: fasting blood glucose; $\mathrm{HbA}_{1 \mathrm{c}}$ : glycated hemoglobin. Values are mean \pm standard deviation.

Table 6. Serum Total Cholesterol, Triglyceride and HDL-Cholesterol

\begin{tabular}{lccc}
\hline & TCh(mg/dl) & TG(mg/dl) & HDL(mg/dl) \\
\hline DM & $216 \pm 48$ & $159 \pm 92$ & $40 \pm 12$ \\
DM+IHD & $216 \pm 50$ & $190 \pm 99$ & $35 \pm 10$ \\
IHD & $205 \pm 42$ & $148 \pm 48$ & $32 \pm 10$
\end{tabular}

TCh: total cholesterol; TG: triglyceride; HDL: high density lipoprotein cholesterol. Value are mean \pm standard deviation.

the diabetic control is slightly better in DM + IHD group than in DM group and intrinsic secretion of insulin may play an important role on the onset and progression of IHD in diabetic subjects.

Serum $\mathrm{Mg}$ levels in DM, DM + IHD and IHD group were similar but significantly lower than that of control subjects. This result suggested that $\mathrm{Mg}$ deficient state was existed in diabetic patients and IHD patients. Hyperglycemia may induces the increase of urinary $\mathrm{Mg}$ excretion and there may be a decrease of $\mathrm{Mg}$ absorption in diabetic subjects. And serum $\mathrm{Mg}$ level of well controlled diabetic patients was slightly higher than that of poorly controlled subjects in this study. Mather H.M. reported that there was close correlation between serum $\mathrm{Mg}$ level and diabetic control state (4). A few case of diabetes were given magnesium sulfate intravenously for several months showed decrease of blood glucose and $\mathrm{HbA}_{1 \mathrm{c}}$ (unpublished observations). These data suggested that $\mathrm{Mg}$ deficient state was one the cause of insulin resistancy.

In IHD patients their serum $\mathrm{Mg}$ level was also decreased. Hypomagnesemia was often observed in acute myocardial infarction, in chronic ischemic heart disease hypomagnesemia was also observed. The use of diuretics in our IHD patient was less than $10 \%$, so diuretics was not contributed to the decrease of serum $\mathrm{Mg}$. $\mathrm{Mg}$ deficiency brought about
Table 7. Magnesium Levels of Serum and Erythrocyte

\begin{tabular}{lcc}
\hline & Serum(mg/dl) & Erythrocyte $(\mathrm{mg} / \mathrm{dl})$ \\
\hline DM & $1.9 \pm 0.37^{*}$ & $4.3 \pm 0.87$ \\
DM+IHD & $1.8 \pm 0.23^{*}$ & $4.5 \pm 0.72$ \\
IHD & $1.9 \pm 0.33^{*}$ & $4.4 \pm 1.2$ \\
Control & $2.3 \pm 0.32$ & $4.5 \pm 1.0$ \\
\hline
\end{tabular}

Values are mean \pm standard deviation. Significance of the differences was $v s$. control. ${ }^{*} p<0.05$.

inhibition of cytosomal $\mathrm{Na}, \mathrm{K}-\mathrm{ATPase}$ and $\mathrm{Ca}$ ATPase activities. Na-Ca exchange mechanism was also disturbed, and $\mathrm{Mg}$ deficiency may introduced cardiovascular disorders $(5,6)$.

These two studies indicate that there were close relation between $\mathrm{Mg}$ and diabetes mellitus and ischemic heart disease.

\section{References}

1. Kondo K, Nozawa $\mathrm{K}$, Tomita $\mathrm{T}$, Ezaki $\mathrm{K}$ : Inbred strains resulting from Japanese mice. Bull Exp Anim 1957; 6: 107-109 (in Japanese).

2. Nakamura M: A diabetic strain of the mouse. Proc Jpn Acad 1962; 38: 348-352.

3. Aikawa JK: Effects of alloxan-induced diabetes on magnesium metabolism in rabbits. Am J Physiol 1960; 199: 1084-1086.

4. Mather HM, Levin GE, Nisbet JA, Hadley LAA, Oakley NW: Diurnal profile of plasma magnesium and blood glucose in diabetes. Diabetologia 1982; 22: 180-183.

5. Altura BM, Altura BT: New perspectives on the role of magnesium in the pathophysiology of the cardiovascular system I. Clinical aspects. Magnesium 1985; 4: 226-244.

6. Altura BM, Altura BT: New perspectives on the role of magnesium in the pathophysiology of the cardiovascular system II. Experimental aspects. Magnesium 1985; 4: 245-271. 